Vol. 39(2), pp. 227-245, Dec. 2020

ISSN 1821-536X (print)

ISSN 2619-8789 (electronic)
Tanzania Journal of Engineering and Technology

Copyright $@ 2020$ College of Engineering and

Technology, University of Dar es Salaam

Review Paper

\title{
Potential for Increased Rural Electrification Rate in Sub-Saharan Africa using SWER Power Distribution Networks
}

\author{
Michael E. Irechukwu and Aviti T. Mushi \\ Department of Electrical Engineering, University of Dar es Salaam, Tanzania. \\ *Corresponding Author E-mail: aviti.bahati@gmail.com
}

\begin{abstract}
Rural electrification rate (RER) in Africa is still low to date. Several countries in Sub-Saharan Africa have tried to address this problem using conventional singlephase two-wire or three-phase three-wire systems, however at large costs due to the nature of dispersed rural load centres, low load demand, and low population density. Another solution of off-grid generation creates associated health problems. Therefore, this paper undertakes a review of a single wire earth return (SWER) network as a RER improvement solution. The paper undertakes intensive literature review to elucidate challenges and solutions to the implementation of SWER technology. Advantages of SWER technology discussed make it the choice for RER improvement in Sub-Saharan African countries. After that, a case study is selected in rural Tanzania, and a preliminary SWER network design is undertaken.
\end{abstract}

Keywords: Single wire earth return (SWER), power distribution networks, rural electrification rate $(R E R)$.

\section{INTRODUCTION}

Majority of grid-connected rural electrification (RE) technology in Africa are the single-phase two-wire (SPTW) distribution system and the three-phase three wire (TPTW) distribution system, called conventional technologies. Mahanthege (2015) cited a study that presented data of rural electrification rate (RER) in Sub-Saharan Africa at about $14.2 \%$. This is an alarming situation that suggests of existence of barriers to achieving higher RER in some perspective. The literature suggests that the first barrier to be high investment cost of installing SPTW and TPTW because of using two or more conductors which necessitate erecting large number of poles to support these heavy lines. For example, the governments of South Africa and Zimbabwe invested huge amounts of money to rural electrification projects using these conventional technologies (Davidson and Mwakasonda, 2004). The second barrier is the scattered rural population which results in low demand per connection, thus producing low benefit-cost-ratio $\left(B_{C R}\right)$. The third barrier is low population density in rural areas with low-income levels, thus resulting to small sized electricity demand. These three are thought to discourage utilities in increasing RER in Sub-Saharan Africa (Golumbeanu and Barnes, 2013). As such to reverse this trend, for these poor countries the access to electricity must preferably be planned as one component of a rural development process (Zoomers, 2014). One might suggest the local 
generation of electricity using available fossil fuels to effectuate RER improvement, as a solution. However, local generators that produce electricity thermally have been shown to cause health problems - diseases of several kinds, in Sri Lanka (SLEMA, 2020). This is due to the fumes, emissions, etc. that are produced as by-products of the electricity generation process. Other places of Africa have proposed RER improvement through solar minigrids such as those found in Kenya, and Uganda (Bahaj et al., 2020). This improved RER act as a bringer of economic improvements to the populations, since technological developments happen with reliable power (Ferguson et al., 2000).

However, there is a technology that uses single wire that can effectively supply scattered rural populations at a supposedly cost-effective method. This technology is called single wire earth return (SWER) distribution system. The technology calls for stringent voltage and current limits observance so that the dangers arising from touch and step potential are alleviated. It was developed and first implemented in New Zealand around 1925 (Mandeno, 1947), then it spread to Australia (Nobbs, 2012). Further, it has been implemented in Sri Lanka (Mahanthege, 2015), Brazil (Luciano et al., 2012), Namibia (Himmel and Huysen, 2002), South Africa (Kessides et al., 2007), Tunisia (Cecelski et al., 2005), Ghana (Iliceto et al., 1989) and Uganda (Bakkabulindi et al., 2012; Bakkabulindi et al., 2009; Da Silva et al., 2001). Realizing the potential of SWER, some researchers suggested it as a feasible electrification for a settlement in Rwanda (Solange, 2017); Tanzania (Irechukwu, 2020; Irechukwu and Mushi, 2021; Meijer, 1995); a minigrid extension in Uganda (Bakkabulindi, 2012); and a future rural electrification plan for Nigeria (FMPWH, 2016). These are very few literatures that elucidate the technical and economic aspect of SWER technology in Africa. This lack of literature causes lack of comprehensive understanding of the benefits and/or drawbacks of SWER technology for Africa, especially the rural applications. For example, a proposed SWER design in Botswana showed drastic cost reduction of about $17.83 \%$ the cost of $33 \mathrm{kV}$ TPTW (Anderson, 2002). Therefore, this paper is an attempt to address this literature and knowledge gap by providing a systemic analysis of available literature and document all benefits and drawbacks that have been or can be accrued by the African countries by utilizing SWER technology.

\section{CHALLENGES LIMITING WORLDWIDE APPLICATIONS OF SWER}

This section presents challenges that plague and as a result limit pervasive applicability of SWER technologies globally and especially Sub-Sahara Africa. These challenges include, but not limited to, high benefit-cost-ratio; low load capacity; high reactive losses (Momoh et al., 2019); more than average energy losses of the conventional technologies; and voltage regulation.

\section{High Benefit-Cost-Ratio}

Rural electrification rate can be measured using a metric called benefit-cost-ratio $\left(B_{C R}\right)$. The ratio should be $B_{C R} \geq 1$ to deliver net value to the utility's project. Others denote it as BCR (Karki, 2004), while others call it benefit cost analysis factor (Parmar, 2016; Sidhu et al., 2018). The RER in Sub-Saharan Africa has slightly increased from $5 \%$ in 2002 (Davidson and Mwakasonda, 2004) to $22 \%$ in 2017 (IEA, IRENA, UNSD, WB, WHO, 2019) due to the costly nature of distribution system installation faced by the utilities. On utilities side, this high $B_{C R}$ is undesirable. On the other hand, rich countries such as US has achieved wider 
access to electricity in the scattered rural communities by subsidizing companies or utilities which install electricity distribution infrastructures (Yuan, 2015), and as such it has provided low-cost technologies for rural electrification, one being the SWER. This has been achieved, for these projects, by realizing low $B_{C R}$ defined as follows (NER, 2001).

$B_{C R}=\frac{P_{v f s} K_{s} K_{v a l}}{D_{1}+D_{o_{-} m}+\left(P_{v f l} L_{r m c} K_{L}\right)}$

Benefit-cost-ratio in (1) incorporates the following variables: the present value for electricity sales denoted as $P_{v f s}$, the amount of electricity in $\mathrm{kWh}$ sold in a year denoted as $K_{s}$, the value of electricity in $\mathrm{kWh}$ denoted as $K_{v a l}$, the discounted value of investment stream denoted as $D_{I}$, the discounted value of operations and maintenance costs each year denoted as $D_{o_{-} m}$, the present value of losses denoted as $P_{v f l}$, the long range marginal cost for distribution denoted as $L_{r m e}$, the $\mathrm{kWh}$ losses in a year denoted as $K_{L}$. However, this is easy to plan for but harder to implement because other factors challenge cheap SWER technology implementation in rural areas because of low consumption (Karki, 2004; Maunsell Limited, 2006; Rudnick et al., 2014). Despite these challenges, Cuba has achieved $28.8 \% B_{C R}$ for its SWER implementation compared if they used the conventional TPTW (Monteagudo, 2014).

\section{Voltage Regulation and Transmission Loss Issues}

Second challenge that faces applicability of SWER system is voltage regulation (VR) and transmission losses. This system can efficiently supply loads connected within $25 \mathrm{~km}$ from the distribution transformers (Louie et al., 2015), thus it can be modelled as a short transmission line. Consider Figure 1 showing a model of this short transmission line of length $l \leq$ $80 \mathrm{~km}$. The variables are: sending end voltage denoted by $V_{S}$, sending end current denoted by $I_{S}$, resistance and reactance expressed as $R$ and $X$ both measured in $\Omega / \mathrm{m}$. Therefore, for line of length $l$ forms line impedance $Z=R+j X$, receiving end current and voltage denoted by $I_{R}$ and $V_{R}$ respectively.

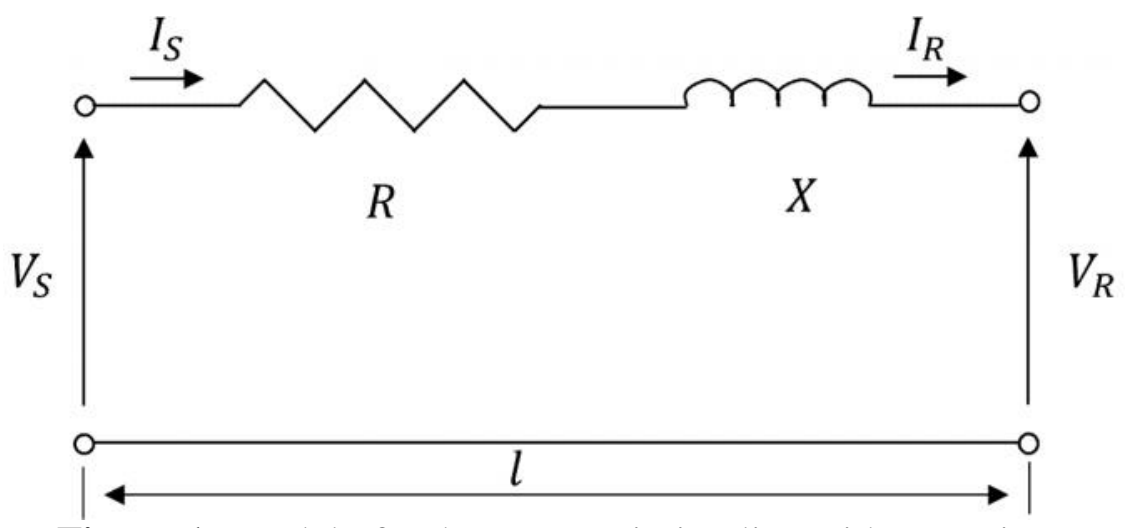

Figure 1: Model of a short transmission line with two wires.

Therefore, using Kirchhoff's current and voltage laws (KVL and KCL) with $A B C D$ parameters, equation (2) is obtained (Grainger and Stevenson, 1994).

$\left[\begin{array}{l}V_{S} \\ I_{S}\end{array}\right]=\left[\begin{array}{ll}A & B \\ C & D\end{array}\right]\left[\begin{array}{l}V_{R} \\ I_{R}\end{array}\right]$
Equation (2) has the following parameters: $A=D=1, \quad B=Z \Omega, \quad$ and $C=0 \mathrm{~S}$. Therefore, line regulation $(V R)$ and line loss $\left(P_{\text {loss }}\right)$ are defined by Equation (3) and (4), respectively. 


$$
\begin{aligned}
& \boldsymbol{V} R=\frac{\left(\left|V_{S}\right| / A\right)-\left|V_{R}\right|}{\left|V_{R}\right|} \times 100 \ldots \ldots \ldots \ldots \ldots \\
& P_{\text {less }}=\left|V_{S}\right|\left|I_{S}\right| \cos \varphi_{S}-\left|V_{R}\right|\left|I_{R}\right| \cos \varphi_{R}
\end{aligned}
$$

These equations contain the following variables: $\varphi_{S}$ and $\varphi_{R}$ are the power factor angle of the sending end and receiving end respectively. The single line design of SWER in Figure 1 poses a challenge to maintain these (3) - (4) in acceptable limits. Here, the deciding factor is the impedance and power factor. Voltage fluctuation (or regulation) is reported to challenge the high penetration of solar photovoltaic (PV) energy into the SWER distribution system (Guinane et al., 2012). Results show voltage rises across the low voltage (LV) network exceeding regulatory standards with the high penetration of PV in SWER networks. These networks could also be fed on both ends using PV and SWER, backed up by a diesel generator in a bidirectional setup, such as the one in Philippines (Sumaya et al., 2019). Technology advances e.g., efficient transformers, better cable design, etc. have enabled the reduction of distribution network losses from $16 \%$ in 1926 to 7\%, globally (ETSAP, 2014).

\section{Carson's Line Model}

Carson (1926) pioneered the derivations that computed the impedances of overhead conductors with earth return. Other researchers (Ciric et al., 2004; Kersting, 2005; Kersting and Green, 2011) used the inspiration of Carson's work to compute the impedances using numerical methods. They considered the Carson's line to be a modification of Figure 1 in the following way. A single return conductor with a selfgeometric mean radius (GMR) of unit length conductor $a-a^{\prime}$ running parallel to the ground (earth), carrying current $I_{a}$, with its return circuit $g-g^{\prime}$ beneath the earth (also known as the fictitious conductor). The return conductor is located at a distance $D_{a g}$ below the overhead line, shown in Figure 2. This $D_{a g}$ depends on the soil resistivity $\left(\rho_{e}\right)$, thus different soils will have different characteristics shown in Table 1 (Samra, 1972). The variable $z_{a a}$ is the self-impedance of the line, $z_{a g}$ is the ground mutual impedance, and $z_{g g}$ is the ground self-impedance.

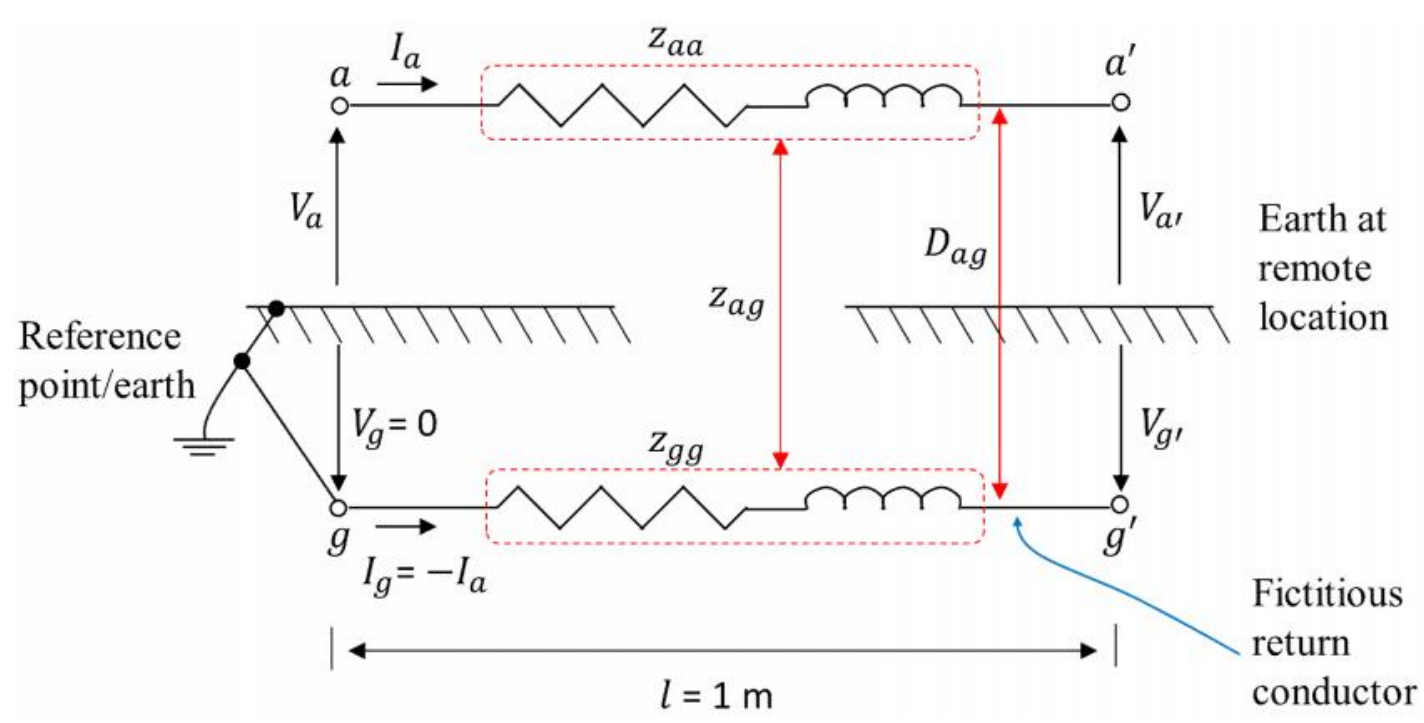

Figure 2: Model of a Carson' line (Ciric et al., 2004) 
Table 1: Soil Resistivity (Source: Samra, 1972)

\begin{tabular}{|l|c|c|c|c|c|}
\hline Ground type & Organic wet soil & Moist soil & Dry soil & Bedrock & Unit \\
\hline Resistivity $\left(\rho_{\Theta}\right)$ & 10 & 100 & 1,000 & 10,000 & $\Omega m$ \\
\hline
\end{tabular}

Using the KVL, the Carson's line equations are obtained as equation (5), which is a modification of equation (2) because of the ground return effect. Where the potential drops $V_{a}, V_{a}, V_{g}$, and $V_{g}$ are all measured with respect to same reference $\left(V_{g}=0\right)$.

$\left[\begin{array}{l}V_{a}-V_{a \prime} \\ V_{g}-V_{g^{\prime}}\end{array}\right]=\left[\begin{array}{ll}z_{a a} & z_{a g} \\ z_{a g} & z_{g g}\end{array}\right]\left[\begin{array}{c}I_{a} \\ -I_{a}\end{array}\right]$

Further manipulation of equation (5) yields the potential $V_{a}$ as the function of line selfimpedance, ground correction factors and the line current, see equation (6). The ground correction factor is approximated by ground self and mutual impedances as $\left(z_{g g}-2 z_{a g}\right)$ in equation (7). Further computations pertaining to equation (7) are outlined by Ciric et al. (2004).

$$
\begin{aligned}
& V_{a}=\left(z_{a a}+z_{g g}-2 z_{a g}\right) I_{a} \equiv Z_{a a} I_{a} \ldots \\
& Z_{a a} \cong z_{a a}+z_{g g}-2 z_{a g} \ldots \ldots \ldots \ldots \ldots
\end{aligned}
$$

\section{Ground Resistance}

Design challenge faced in the installation of SWER system is ensuring that the earth resistance $\left(r_{\varepsilon}\right)$ at the isolation and distribution transformer is within acceptable limits (Nebi et al., 2017; Solange, 2017). The isolation transformer is very important because it is often used to prevent the SWER ground currents from causing earth current faults on the main medium voltage (MV) network. There have been cases of burning of earthing electrodes and wooden poles due to poor earthing (Catriz et al., 2019; Nobbs, 2012), and this is expensive as this hardware has to be replaced after every burning. To avoid such dangers and costs, the installation site must possess low or medium earth resistivity $\left(\rho_{e}\right)$, because this allows cheap cost of grounding the earthing electrodes and protection of equipment (Iliceto et al., 1989). Therefore, it is of utmost importance to prevent dry out soil by fast evaporation near the electrodes, as this will cause an uncontrolled increase in resistance and cause thermal instability, which is checked by employing Ollendorff formula (Iliceto et al., 1989).

$V_{e}=\sqrt{2 \lambda \rho_{e} \theta_{\theta}}$

Where $V_{e}$ is potential of electrode above that of earth; $\lambda$ is heat conductivity of the soil; and $\theta_{\theta}$ is the temperature rise of the electrodes and contiguous soil above the ambient. Soil resistivity is affected by $\theta_{e}$, moisture, and percentage of salts in the soil. Practically, for $50 \mathrm{~Hz}$ currents, the earth path that allows the current to flow is limited by the skin depth $(\delta)$. Conservatively, the current density should not exceed $200 \mathrm{~A} / \mathrm{m}^{2}$, in the vicinity of the grounded electrode for more than one second (Meijer, 1995). The efficient grounding was experimentally shown to result to maximum and efficient power transfer (Neste et al., 2016), albeit that was a wireless system.

\section{Limited Power Handling Capability}

Power is supposed to flow with minimal losses in a SWER network, as was previously shown by equation (4). Using Figure 2 and taking node $i$ to enclose point $a$ and node $j$ to enclose point $a^{\prime}$ then the power flow can be computed by Equations (9) - (11) observing the power mismatch criteria equations (12) - (13). The variables are explained as following: - $I_{\text {ia }}$ and $I_{i g}$ are current injections at node $i$; 
$S_{i a}$ and $S_{i g}$ are the scheduled power injection at node $i ; Y_{i a}$ is the admittance of all shunt elements at node $i ; Y_{\text {iag }}$ is the admittance of all ground mutual shunt elements; $V_{i a}$ and $V_{i g}$ are phase voltage and ground voltage at node $i ; I_{l a}$ and $I_{l g}$ are current flowing on a section $l$ of the SWER line; $m \in M$ is the set of line sections connected downstream to node $j$; and $\Delta S_{i a}$ and $\Delta S_{i g}$ are power mismatches at node $i$.

$$
\begin{aligned}
& {\left[\begin{array}{l}
I_{i a} \\
I_{i g}
\end{array}\right]=\left[\begin{array}{c}
S_{i a} / V_{i a}^{*} \\
-I_{i a}
\end{array}\right]-\left[\begin{array}{cc}
Y_{i a} & Y_{i a g} \\
Y_{i a g} & 0
\end{array}\right]\left[\begin{array}{l}
V_{i a} \\
V_{i g}
\end{array}\right] . .} \\
& {\left[\begin{array}{c}
J_{l a} \\
J_{l g}
\end{array}\right]=-\left[\begin{array}{c}
I_{j a} \\
I_{j g}
\end{array}\right]+\sum_{m}^{M}\left[\begin{array}{c}
J_{m a} \\
J_{m g}
\end{array}\right] \ldots \ldots \ldots(10) \ldots \ldots} \\
& {\left[\begin{array}{c}
V_{j a} \\
V_{j g}
\end{array}\right]=\left[\begin{array}{c}
V_{i a} \\
V_{i g}
\end{array}\right]-\left[\begin{array}{ll}
Z_{a a} & Z_{a g} \\
Z_{a g} & Z_{g g}
\end{array}\right]\left[\begin{array}{l}
J_{l a} \\
J_{l g}
\end{array}\right] \ldots \ldots} \\
& \Delta S_{i a}=V_{i a}\left(I_{i a}\right)^{*}-Y_{i a}^{*}\left|V_{i a}\right|^{2}-S_{i a} \ldots . .(12) \\
& \Delta S_{i g}=V_{i g}\left(I_{i g}\right)^{*} \ldots \ldots \ldots \ldots \ldots \ldots \ldots
\end{aligned}
$$

Single wire earth return networks can reach their power and voltage design capacity due to unprecedented electrical demand brought about by proliferation of end user loads. When this happens, switched capacitors can be employed to provide voltage support (Shammah et al., 2013). This solution was also deployed by Ergon Energy (Lowry et al., 2012). Ergon implemented it in the Queensland's 64,000 $\mathrm{km}$ of SWER networks and its efficacy was verified experimentally. In addition, they alleviate or reduce charging capacitance current associated with Ferranti effect on long SWER lines. Distribution static compensators (DSTATCOM) discussed by Mirazimiabarghouei (2017) and Mirazimiabarghouei et al. (2016) are installed to regulate the flow of reactive power by injecting or absorbing it from the distribution networks, when the need be, to improve voltage profile, power factor, and voltage stability of the network.

\section{Improving Voltage Profile}

Voltage profile of a SWER line can be improved using single phase voltage regulators. However, these may not function so well if a large increase on load demand on SWER line happens with accompanied voltage distortions or VR (Hosseinzadeh et al., 2011). In this case an upgrading of a SWER system to handle this VR problem is proposed using either switched reactors, saturable reactors (Mayer et al., 2006) or DSTATCOMS. However, this comes at a high cost to the installation (Mirazimiabarghouei, 2017). The DSTATCOMS works better whenever they are installed on the customer side to provide the needed voltage support, rather than upstream in the network. The DSTATCOMS can cause peak value of line voltage limit at the customer terminal by injecting active $(P)$ and reactive $(Q)$ power at constant apparent power $(S)$. This action ensures stable operation of the line.

Other studies (Kashem and Ledwich, 2004; Kashem and Ledwich, 2002) proposed installation of distributed generators (DG) in the SWER network to aid in improving voltage profiles, reduce the system losses as well as costs (Hosseinzadeh and Rattray, 2008; Vo et al., 2013). These DGs control system is set to respond very fast to system changes, thus performs power factor correction and correct any VR while at the same time helping to reduce power losses in the SWER system. System reliability is improved as well. The reliability improvement is due to the SWER design being able to carry less reactive and active losses in the system compared to the conventional technologies (Bank, 2018). 


\section{THE DESIGN OF SWER DISTRIBUTION SYSTEM}

Single wire earth return (SWER) system is composed of the following components (Brooking et al., 1992): (1) isolation transformer with rated voltage $11 \mathrm{kV} / 6.35$ $\mathrm{kV}$ and power rating $25-300 \mathrm{kVA}$; (2) distribution primary $6.35 \mathrm{kV}$ and two secondary low voltages of $230 \mathrm{~V}$ or $240 \mathrm{~V}$; (3) aluminium steel clad steel reinforced (ACSR) conductor; (4) earthing system which also is the return path; (5) support poles - either stainless steel or wooden; and (6) the transformer secondary is protected by a standard high-rupture capacity (HRC) fuse or low voltage circuit breaker. Figure 3 shows the complete SWER distribution system from the grid to the customer supply side.

\section{Safety Feature of SWER Line}

The SWER line does not use the common electrical safety feature - since it lacks a traditional metallic return to a neutral shared by the generator. Instead, the safety is assured from its design of isolation transformers. These isolate the ground from both the generator and user. However, still there is possibility of stray voltages injuring people and livestock in the vicinity of the line. Therefore, grounding is critical to ensure that only 8 $\mathrm{A}$ is the limit of ground current flowing (Grad, 2014). These earth grounds are duplicated to assure increased safety.
Duplication of the ground points assures that the system is still safe if either of the grounds is damaged. In fact, the duplicated ground in SWER leads to zeroing (Bank, 2012) because the resistance on the ground between them is much greater than the resistance of the wire.

\section{Cost Structure of SWER Network Comparing with Conventional Technologies}

The SWER network attracts capital costs at around $55.5 \%$ of an equivalent SPTW network (EU Energy Initiative, 2015). In addition, SWER cost is about $40 \%$ of a TPTW network costs. One might ask, how does the cost saving occur? The answer is the massive reduction in the hardware to be used in SWER erection as compared to those conventional methods. Pragmatically, it can be looked at as follows: TPTW requires seven (07) poles per $\mathrm{km}$ with spans of 100 to $150 \mathrm{~m}$; while SWER requires spans of about $400 \mathrm{~m}$ thus reducing the poles per $\mathrm{km}$ to 2.5 poles (The World Bank, 2006).

On its entirety, SWER distribution system is a very simple structure to construct because it only requires one live wire and the earth as return conductor. However, this is easier said than what the actual construction takes, since lack of technical know-how limits its applicability in SubSahara region. 


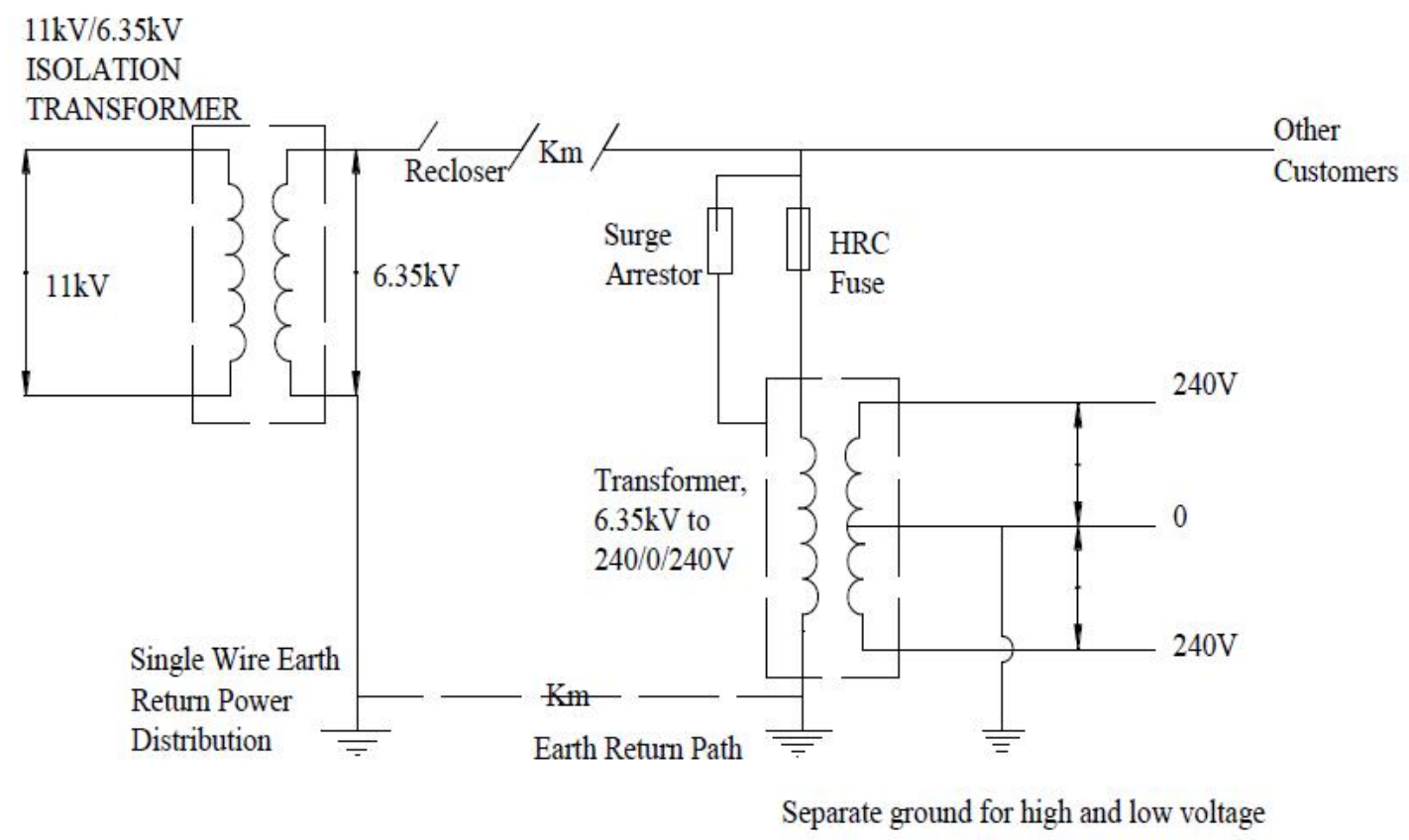

Figure 3: Configuration of SWER distribution system -isolation transformer rated 11 $\mathrm{kV} / 6.35 \mathrm{kV}$, distribution transformer rated $6.35 \mathrm{kV} / 240 \mathrm{~V}$, and customer side

\section{The limited technical know-how}

Despite the envisaged low investment costs required for SWER implementation, the technology has not been widely incorporated into power distribution planning in Sub-Saharan Africa, thereby rendering vast regions un-electrified. This is thought to be brought about by limited or lack of sufficient technical know-how that is prevalent in many utilities in the region. In 2010, it was estimated that some 2.5 million new engineers and technicians would be needed in sub-Saharan Africa alone if that region is to achieve some of the Millennium Development Goals (UNESCO, 2010). For example, in Tanzania, the University of Dar es Salaam currently graduates about 60 electrical engineering students per year. The situation in other regions of sub-Saharan Africa is not very much different. That number of skilled engineering graduates is not enough to allow fully devotion to work on SWER technology, to reap its benefits. However, with time and proper investment in engineering education, this trend might change for the better (The World Bank, 2014).

\section{SWER TECHNOLOGIES IN AFRICAN COUNTRIES}

Australia has always been a leader in application of SWER technology. For example, by year 2012 she had installed total of $64,000 \mathrm{~km}$ of SWER lines (Lowry et al., 2012). This is a big contrast to the few African countries that have installed few $\mathrm{km}$ of SWER technology to increase RER so that they may improve quality of life (Karki, 2004). African countries that have successfully installed SWER are Namibia (Momoh et al., 2019), Tunisia, and South Africa. In this section, the paper will present the implications of the SWER on RER of these mentioned countries.

\section{Namibia}

Prior to 1998, Namibia power utility, namely NamPower used to connect to the grid about 5,700 rural households annually at a cost of US\$ 923 per connection (Himmel and Huysen, 2002; AEI, 2012). This trend changed when the utility adopted SWER technology, for whence the connections rose to 14,800 rural 
households connected annually at a cost of US\$ 384.6 per connection. Table 1 shows this $260 \%$ connection increment at a reduction of $40 \%$ of the cost per connection scenario comparing to before SWER, which is thus an improved RER.

Table 1: Costs and connections before and after SWER adoption in Namibia (AEI, 2012; Himmel and Huysen, 2002)

\begin{tabular}{|l|c|c|}
\hline Period & Cost (US\$/Connection) & Connections/Year \\
\hline Before 1998- conventional & 923 & 5,700 \\
\hline After 1998 - adoption of SWER & 384.6 & 14,800 \\
\hline
\end{tabular}

\section{South Africa}

Eskom, the power utility of South Africa adopted SWER applications in the year 1992 (Eskom, 1996). This move boosted the RER from $28 \%$ to $42 \%$ by 2001 (AEI, 2012). Consider this, before the year 1992 , about 80,000 rural connections were made per year. With SWER adoption, this number changed to 390,000 rural connections per year (NER, 2001). This was possible because the connection costs dropped from US\$1,000 per connection to US\$ 445, and as a result the SWER's cost per km became US $\$ 3,650$ a very low $B_{C R}$, therefore, profitable to the utility and thus Table 2 displays this improvement scenario.

Table 2: Costs and connections before and after SWER adoption in South Africa (AEI, 2012; Eskom, 1996; NER, 2001)

\begin{tabular}{|l|c|c|}
\hline Period & Cost (US\$/Connection) & Connections/Year \\
\hline Before 1992 - conventional & 1,000 & 80,000 \\
\hline After 1992 - adoption of SWER & 445 & 390,000 \\
\hline
\end{tabular}

\section{Tunisia}

The progressive Tunisian government had made increased RER one of its development goal in the mid-1970s, reaching a $6 \%$ RER. Through her utility company, Tunisian Electricity and Gas Company (Société de l'Electricité et du $\mathrm{Gaz}$ - STEG) the country invested massively in rural electrification (Cecelski et al., 2005). The company decided to use a different technology from the conventional - SPTW and TPTW, called Mise A La Terre (MALT) which is a three phase-phase/single-phase technology (Karhammar et al., 2006). Between 1977 to 1986 , MALT enabled to raise the RER to $28 \%$ because of dramatic costs reduction, thus exceeding targets repeatedly. After learning about advantages realized with SWER installation, STEG gave it a shot in the 1990s so that they could increase the RER. During the SWER implementation, a cost reduction of 26-30\% as compared to MALT was realized (Cecelski et al., 2005). STEG electrified about 425 villages in a span of six years. Further implementation of SWER up to year 2000s, achieved an $88 \%$ RER - about 600,000 rural connections per year. Then consistent efforts realized 97\% RER by year 2012 (AEI, 2012). The World Bank reported a $37 \%$ cost reduction when using SWER as opposed to conventional technologies (World Bank, 2006). The information discussed in this section is encapsulated by Table 3, showing the RER increment and massive cost reduction by implementing SWER. 
Table 3: Costs and connections before and after SWER adoption in Tunisia (Cecelski et al., 2005; World Bank, 2006)

\begin{tabular}{|l|c|c|}
\hline Period & Cost (US\$/Connection) & Connections/Year \\
\hline Before 1990s - conventional and MALT & 1,350 & 28,500 \\
\hline After 1990s - adoption of SWER & 670 & 135,000 \\
\hline
\end{tabular}

\section{RURAL ELECTRIFICATION IN SOUTHERN AFRICAN COUNTRIES}

In Southern African Development Community (SADC), cost of rural electrification by grid extension to small, remote and dispersed loads is expensive, featuring high $B_{C R}$ thus leading to energy poverty (Gonzalez-Eguino, 2015). This has acted as the main barrier for financing projects that will increase RER, thereby, forcing these countries governments to rely heavily on foreign aid (Kimambo and Nielsen, 2012). However, in 2009, these countries resolved to tackle the RER improvement issues on Member States level (SADC, 2010). One proposed strategy put forth by SADC is the use of SWER. Table 4 shows the RER discrepancy between Southern Africa Development Community (SADC) countries that had adopted SWER and those who didn't by the year 2006. Those few who had not adopted SWER exhibited less than 10\% RER. This shows the promise held by application of SWER technology to the overall rural electrification of SADC countries.

Table 4: Rural electrification levels in SADC Countries in year 2006 (Kapika and Oguah, 2018; Kimambo and Nielsen, 2012; SADC Statistical Yearbook, 2015)

\begin{tabular}{|l|c|c|c|}
\hline Country & Population (millions) & Rural population (millions) & RER (\%) \\
\hline Tanzania & \multicolumn{1}{|c|}{${ }^{1}$} & 30.28 & $49.3^{2}$ \\
\hline Angola & 20.23 & 9.1 & 4 \\
\hline Botswana & 1.8 & 0.8 & 9 \\
\hline DRC & 55.6 & 37.4 & 2 \\
\hline Lesotho & 1.9 & 1.5 & 1 \\
\hline Malawi & 12.8 & 10.5 & 1 \\
\hline Mozambique & 20.1 & 13.8 & 2 \\
\hline Namibia & 2 & 1.3 & 50 \\
\hline South Africa & 48.2 & 19.4 & 3 \\
\hline Zambia & 11.6 & 7.5 & 8 \\
\hline Zimbabwe & 12 & 7.6 & 5 \\
\hline Eswatini & 1.2 & 0.8 & \\
\hline
\end{tabular}

${ }^{1}$ Tanzania was not a SADC member in year 2006

${ }^{2}$ Tanzania RER for 2006 was not obtained, therefore authors used the data of 2013

\section{CASE STUDY IN TANZANIA}

Up to this point, the authors have reviewed the applications of SWER, its challenges, and its advantages in the SADC countries. It was shown that it is possible to assist other development efforts to improve RER through the technology. In the outset, up to 2016, Tanzania's $46 \%$ power consumption of rural areas comes from off-grid generators (Eberhard et al., 2016). To avoid planning RE as an emergency, it is better to partake normal conditions planning as suggested by Khator and Leung (1997) because of its advantages. This is suggested because of the activities involved - planning for the power flow, feeder and substation installation, and others. Therefore, this section selects a 
model rural location in Tanzania and design the electrification scheme from the grid, using SWER (Irechukwu, 2020; Irechukwu and Mushi, 2020; Irechukwu and Mushi, 2021). This village is called Homboza, located in Pwani (Coast) Region of Tanzania at coordinates: $7.3238^{0} \mathrm{~S}$ and $38.8205^{\circ} \mathrm{E}$. It has a population of about 1,565 people, where the economic activities are small scale agriculture. The reason to select this location is to impart benefits of electrification to the community, which were shown in another similar location in Tanzania (Ngowi et al., 2019), India (Jamasb et al., 2015), and Zimbabwe (Davidson and Mwakasonda, 2004). Further, grid connection feasibility depends on community size and the distance from the closest grid point (Juanpera et al., 2020; Karhammar, 2006), and for the case study of this paper, the community size is sparse populated, about $20 \mathrm{~km}$ from the grid, and rural location. Da Silva et al. (2001) showed a cost saving of $29 \%$ for a RE in Uganda, if SWER is used to connect about 200,000 inhabitants of rural remote areas. It should be noted that Uganda and Tanzania are geographical neighbours, so a solution working in one can be applied with little adaptation to another, case in point the Ntenjeru village (Bakkabulindi et al., 2009). This is interesting, because few years back in the 1990s, Meijer (1995) had already proposed electrifying Tanzania rural areas using SWER technology. Current task here is cementing that work started those times back and working out a possible implementation, starting with load demand estimation.

\section{Load Demand of Homboza}

Field data were collected for 24-hour electrical power usage by fittings and appliances used in typical houses, and those that the villagers wanted to use, but did not have at the moment (Figure 4). The estimated peak load was about $139.7 \mathrm{~kW}$.
This data was used to design and size the transformer shown by Table 5 followed by a SWER line design shown in Table 6 for the $20 \mathrm{~km}$ length. This design is based on consultations with Rural Energy Authority (REA) engineers and the data they provided. Further, note that instead of using single $200 \mathrm{kVA}$ transformer, the design has chosen two transformers rated $100 \mathrm{kVA}$ each (Table 6). Bakkabulindi et al. (2013) specified ACSR for Uganda SWER network, similarly this paper chooses the same for Homboza. All these specifications and other materials are displayed in Table 6. The grounding is proposed using readily available materials such as animal dung and wood coal to fasten the attainment of results and minimizing cost, similar to what Adesina and Akinbulire (2020) proposed in Nigeria. Earth resistance tests are planned to be carried out annually on all the transformers using earth resistance tester (Agugharam et al., 2020), so that if any problems are present, they can be arrested before they can cause damage.

\section{Possible Future Expansion due to Increased Demand}

The $20 \mathrm{~km}$ long SWER line designed for the Homboza village can be expanded to increase its capacity (Wolfs, 2005) or convert to TPTW system, if and when the load demand warrants it. These loads can be pump applications which work efficiently on three-phase power. The conversion can be achieved by a converter technology developed by an engineer named Charles F. Scot in the late 1890s. The technology bears his name - Scot Transformer (Wolfs, 2013). Technical details about how to design the Scot Transformer are covered in detail by Wolfs (2013). The second option to choose from for the case of increased load growth is to upgrade the network to medium voltage SWER network using the customer data (Hosseinzadeh and Mastakov, 2008). This method will provide real time solution to 
the actual load growth observed giving accurate required capacity upgrades. The third capacity enhancement technique is to employ controllable reactors which can increase the capacity to about $85 \%$ as was the case for the North Jericho SWER line (Wolfs, 2005; Wolfs et al., 2007) and Central Queensland line (Hesamzadeh et al., 2008).

The 240-0-240 V distribution transformer may enable the connection of motors rated $480 \mathrm{~V}$ at less than $12 \mathrm{~kW}$ power demand (Bakkabulindi, 2012; Monteagudo, 2014). These motors would still require the power electronic starters to alleviate the big voltage dip during the starting. In addition,there is a demonstrated technology that uses three-phase-to-singlephase power quality conditioner, that can be used to supply nonlinear loads, and three-phase inductive or capacity loads (Da Silva and Negrao, 2018). This technology adopts a dual compensation strategy, which works by drawing sinusoidal current that is in phase with the voltage thus producing high power factor. It further suppresses grid voltage harmonics and eliminate (or compensate) for other disturbances such as voltage sags.

To make the SWER network robust, reliable, and make it long living it is possible to monitor it using power line communications (PLC). One technology narrow band communication channels was suggested and tested by several researchers (Nkom, 2017; Nkom et al., 2018). Another is pole mounted monitoring units installed on the SWER feeder (Song et al., 2017). This monitoring will enable regulation and maintenance of this network using dynamic devices (Gay et al., 2009). Further, some algorithms can be used to detect and protect SWER network against faults, such as high impedance faults (Kavi et al., 2016) so that the reliability is preserved. These must go hand in hand by proper estimation of the costs of distribution systems installation, as historically $60 \%$ of total power costs is used up in the installation works (Baughman and Bottaro, 1975). The cost allocation must be properly handled so that the SWER connected customers are not heavily charged; rather their life must be improved by low-cost technology.

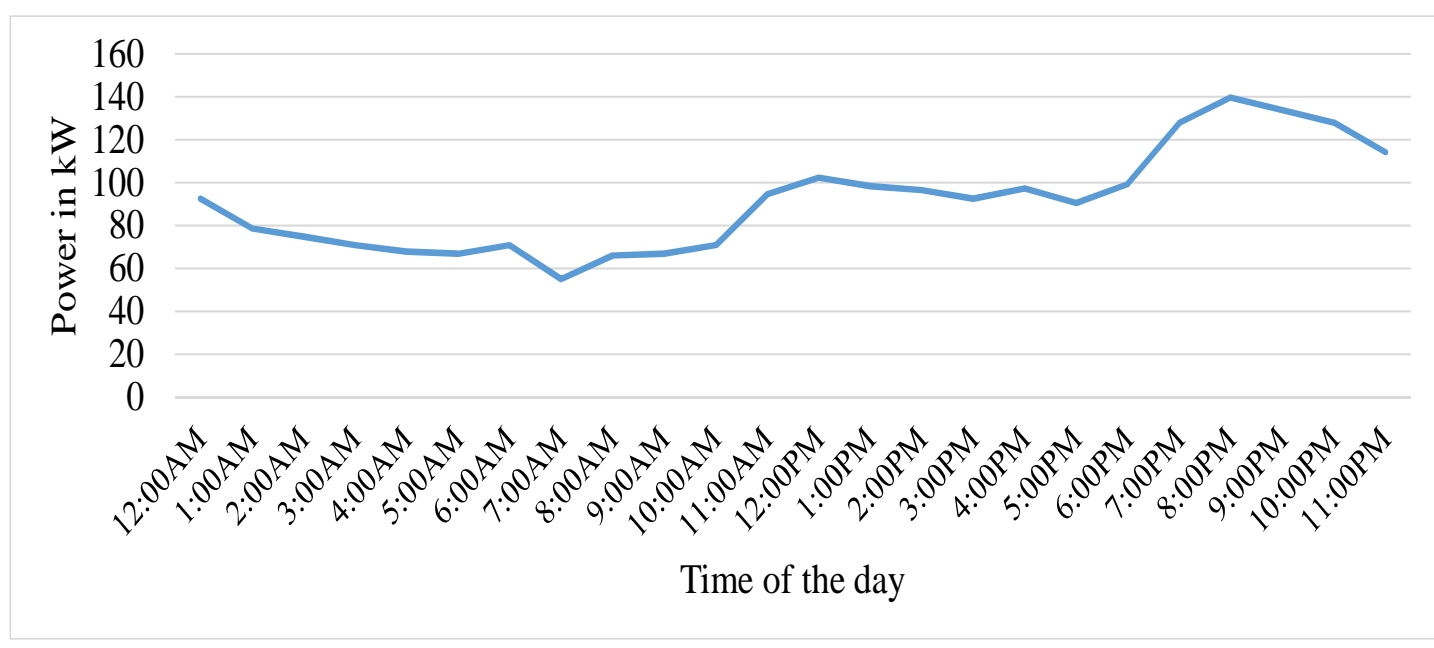

Figure 4: Current load demand projected for Homboza Village in 24 hours 
Table 5: Distribution transformer size for electrifying Homboza village

\begin{tabular}{|l|c|}
\hline Parameter & Value \\
\hline Peak total load for 171 households & $139.707 \mathrm{~kW}$ \\
\hline Power factor & 0.91 \\
\hline Peak apparent power & $153.524 \mathrm{kVA}$ \\
\hline Multiplying factor & 1.3 \\
\hline Transformer rating & $200 \mathrm{kVA}$ \\
\hline
\end{tabular}

Table 6: Material and equipment to connect SWER from grid to Homboza village

\begin{tabular}{|l|c|c|}
\hline Material & Quantity & Unit \\
\hline Wooden pole $(9 \mathrm{~m}$ long$)$ & 250 & Pieces \\
\hline Distribution transformer $(100 \mathrm{kVA}, 11 \mathrm{kV} / 0.23 \mathrm{kV})$ & 2 & Pieces \\
\hline ACSR $\left(50 / 25 \mathrm{~mm}^{2}\right)$ & 20 & $\mathrm{~km}$ \\
\hline Pole-top assembly $($ pin insulator, bolts, nuts) & 250 & Pieces \\
\hline Copper earth rod $(4 \mathrm{ft}=1.22 \mathrm{~m})$ & 4 & Pieces \\
\hline Copper earth rod connector & 4 & Pieces \\
\hline
\end{tabular}

\section{CONCLUSIONS}

This paper has reviewed the SWER technology from its inception to its applicability to increase RER in SubSaharan Africa countries. Challenges that must be solved by utilities to adopt the SWER technology have been outlined and some solutions discussed. It was shown how few Sub-Saharan Africa countries benefitted from SWER technology. Then this technology was suggested for Homboza village found in Tanzania. A preliminary design was presented. Measures to upgrade and protect this designed SWER network were laid out. Future work might focus to perform detailed design and cost analysis of the Homboza SWER network, and use the result for projections to other rural areas to raise the RER within Tanzania.

\section{REFERENCES}

Adesina L.M. and Akinbulire, T.O. (2020). Grounding Method for Reliable Operation of Power and Distribution Transformers Susbtations." Chapter 10 in Emerging Issues in Science and Technology, 4: 105-117. DOI: 10.9734/bpi/eist/v4.
Agugharam T.O., Idoniboyeobu D.C. and Braide S.L. (2020). Improvement of Earthing System for Sub Transmission Station. IRE Journals, 4(4): 62-70.

Anderson G.O. (2002). Rural Electrification in Botswana-A Single Wire Earth Return Approach. Pakistan Journal of Information and Technology, 1(2): 202-207. DOI: 10.3923/itj.2002.202.207

Bahaj A.S., Alam M., Blunden L.S., James P.A.B. and Kiva I. (2020). Pathways to Universal Electricity Access for Rural Communities in Africa. IOP Conf. Series: Earth and Environmental Science 588, 022047, 1-8. doi:10.1088/1755-1315/588/2/022047.

Bakkabulindi G. (2012). Planning Models for Single Wire Earth Return Power Distribution Networks. Licentiate Thesis. Royal Institute of Technology, Stockholm, Sweden

Bakkabulindi G., Da Silva I.P., Lugujjo E. et al., (2009). Rural Electrification Practicalities of Using Single Wire Earth Return as a Low-Cost Method for Grid Extension: The Case of Ntenjeru, 
Uganda. International Conference on Energy and Sustainability, 33-38.

Bakkabulindi G., Hesamzadeh M.R., Amelin M. and Da Silva I.P. (2012). Planning Algorithm for Single Wire Earth Return Distribution Networks. 2012 IEEE Power and Energy Society General Meeting, 1-7. DOI: 10.1109/PESGM.2012.6344816.

Bakkabulindi G., Hesamzadeh M.R., Amelin M. and Da Silva I.P. (2013). Models for Conductor Size Selection in Single Wire Earth Return Distribution Networks. IEEE Africon, 1-5. DOI: 10.1109/AFRCON.2013.6757773.

Bank M. (2018). Electrical Energy Transmission by Several Wires and Reactive Power Problems. Engineering, 10: 329-335. .http://www.scirp.org/journal/eng, ISSN Online: 1947-394X, ISSN Print: 19473931.

Bank M. (2012). Single Wire Electrical System. Engineering, 4: 713-722, http://dx.doi.org/10.4236/eng.2012.411 $\underline{092}$.

Baughman M.L. and Bottar, D.J. (1975). Electric Power Transmission and Distribution Systems: Costs and Their Allocation. IEEE Transactions on Power Apparatus and Systems, PAS95(3): $\quad 782-790 . \quad$ DOI: $\underline{10.1109 / T-}$ PAS.1976.32161

Brooking T.R., Van Rensburg J. and Fourie R.J. (1992). The Improved Utilisation of Existing Rural Networks with the Use of Intermediate Voltage and Single Wire Earth Return Systems. 3rd AFRICON Conference, 228-234. DOI:10.1109/AFRCON.1992.624461

Carson J.R. (1926). Wave Propagation in Overhead Wires with Ground Return. Bell System Technical Journal, 5: 539554.

Catriz R., Ahfock T. and Worden J. (2019). An Investigation into Wooden Pole Fire Inception Threshold in a Single Wire Earth Return System under Drought Conditions. 29 ${ }^{\text {th }}$ Australasian Universities Power Engineering
Conference (AUPEC), 1-6. DOI:10.1109/AUPEC48547.2019.2119 14.

Cecelski E., Ounalli A., Aisaa M., Dunkerley J. (2005). Rural Electrification in Tunisia: National Commitment, Efficient Implementation and Sound Finances. Energy Sector Management Assistance Programme (ESM 307/05). Washington, DC.: World Bank. Available at https://openknowledge.worldbank.org/h andle/10986/18065 License: CC BY 3.0 IGO.

Ciric R.M., Ochoa L.F. and Padilha A. (2004). Power Flow in Distribution Networks with Earth Return. Electrical Power and Energy Systems, 26: 373380. doi: 10.1016/j.ijepes.2003.11.006.

Da Silva I.P., Mugisha P., Simonis P., Turyahikayo G.R. (2001). The Use of Single Wire Earth Return (SWER) as a Potential Solution to Reduce the Cost of Rural Electrification in Uganda. Domestic Use of Energy Conference, 78-79.

Da Silva S.A.O. and Negrao F.A. (2018). Single-Phase to Three-Phase Unified Power Quality Conditioner Applied in Single Wire Earth Return Electric Power Distribution Grids. IEEE Transactions on Power Electronics, 33(5): $\quad 3950-3960 . \quad$ DOI: 10.1109/TPEL.2017.2723573.

Davidson O. and Mwakasonda S.A. (2004). Electricity Access for the Poor: A Study of South Africa and Zimbabwe. Energy for Sustainable Development, 8(4): 26-44. DOI: 10.1016/S0973-0826(08)60511-6

Eberhard A., Gratwick K., Morella E. and Antmann P. (2016).Independent Power Projects in Sub-Saharan Africa-Lessons from Five Key Countries. Directions in Development. Washington, DC: World Bank. doi:10.1596/978-1-4648-0800-5.

Energy Technology Systems Analysis Programme (ETSAP). (2014). Electricity Transmission and 
Distribution. IEA ETSAP-Technology

Brief E12, 1-16.

Eskom (1996). Annual Report. Sandton: Eskom.

EU Energy Initiative. (2015). Low-Cost Grid Electrification Technologies: A Handbook for Electrification Practitioners. Eschborn: EU Energy Initiative.

Federal Ministry of Power, Works and Housing (FMPWH) (2016). Rural Electrification Strategy and Implementation Plan (RESIP). Federal Ministry of Power, Works and Housing-Nigeria.

Ferguson R., Wilkinson W. and Hill R. (2000). Electricity Use and Economic Development. Energy Policy, 28(13): 923-934.

DOI: $10.1016 / \mathrm{S} 0301-$ 4215(00)00081-1

Gay D., Thompson A., Amanulla M.T.O. and Wolfs P. (2009). Monitoring of Single Wire Earth Return Systems using Power Line Communication. 2009 Australasian Universities Power Engineering Conference, 1-5.

Golumbeanu R. and Barnes D. (2013). Connection Charges and Electricity Access in Sub-Saharan Africa. Policy Research Working Paper No. 6511. Washington, DC.: World Bank. https://openknowledge.worldbank.org/h andle/10986/15871 License: CC BY 3.0 IGO.

Gonzalez-Eguino M. (2015). Energy Poverty: An Overview. Renewable and Sustainable Energy Reviews, 47: 377385.http://dx.doi.org/10.1016/j.rser.201 5.03.013.

Grad P. (2014). SWER Still Going Strong. https://www.esdnews.com.au/swer-stillgoing-strong/ accessed on $25^{\text {th }}$ July 2019.

Grainger J.J. and Stevenson W.D. (1994). Power System Analysis. New York: McGraw Hill.

Guinane A., Shafiullah G.M., Oo A.M.T. and Harvey, B.E. (2012). Voltage Fluctuations in PV Penetration on SWER Networks-A Case Study for
Regional Australia. 2012 IEEE Power and Energy Society General Meeting, $1-6$.

DOI:

10.1109/PESGM.2012.6344630.

Hesamzadeh M.R., Hosseinzadeh N. and Wolfs P.J. (2008). Design and Study of a Switch Reactor for Central Queensland SWER System. 43rd International Universities Power Engineering Conference, 1-5. DOI: 10.1109/UPEC.2008.4651481.

Himmel R. and Huysen R. (2002). Northern Electricity Distribution Service in Northern Namibia: A Case Study in the Private Provision of Rural Infrastructure. California: EMCON Consulting Group.

Hosseinzadeh N. And Mastakov S. (2008). Load Modeling for Medium Voltage SWER Distribution Networks. 2008 Australian Universities Power Engineering Conference (AUPEC'08), $1-5$.

Hosseinzadeh N., Mayer J.E. and Wolfs P.J. (2011). Rural Single Wire Earth Return Distribution NetworksAssociated Problems and CostEffective Solutions. Electrical Power and Energy Systems, 159-170. doi: 10.1016/j.ijepes.2010.08.009.

Hosseinzadeh N. and Rattray J. (2008). Economics of Upgrading SWER Distribution Systems. 2008 Australasian Universities Power Engineering Conference (AUPEC'08), $1-7$.

IEA, IRENA, UNSD, WB, WHO. (2019). Tracking SDG 7. The Energy Progress Report 2019, Washington DC.

Iliceto, F., Cinieri, E., Casely-Hayford, L. and Dokyi, G. (1989). New concepts on MV distribution from insulated shield wires of HV lines: Operation results of an experimental system and applications in Ghana. IEEE Transactions on Power Delivery, 4(4): 2130-2144. DOI: $10.1109 / 61.35640$

Irechukwu M.E. (2020). Feasibility Analysis of Using Single Wire Earth Return Medium Voltage Distribution 
Network for Homboza Village Electrification. M.Sc. Dissertation. University of Dar es Salaam, Tanzania.

Irechukwu M.E. and Mushi A.T. (2020). Feasibility Analysis of Using SWER for Homboza Village Electrification. $6^{\text {th }}$ International Conference in Mechanical and Industrial Engineering (MIE2020), $1-6$.

Irechukwu M.E. and Mushi A.T. (2021). Proposal for Single Wire Earth Return Distribution System for Homboza Village Electrification. International Journal of Mechatronics, Electrical and Computer Technology (IJMEC), 11(39): 4837-4842. ISSN: 2305-0543 (Online), ISSN: 2411-6173 (Print).

Jamasb T., Nepal R. and Timilsina G.R. (2015). A Quarter Century Effort yet to Come of Age: A Survey of Power Sector Reforms in Developing Countries. Working Paper. Washington, D.C., World Bank Group. https://openknowledge.worldbank.org/h andle/10986/22211.

Juanpera M., Blechinger P., Ferrer-Marti L., Hoffmann M.M. and Pastor R. (2020). Multicriteria-Based Methodology for the Design of Rural Electrification Systems. A Case Study in Nigeria. Renewable and Sustainable Energy Reviews, 133: 1-16. https://doi.org/10.1016/j.rser.2020.1102 $\underline{43}$.

Kapika J.M. and Oguah S.K.E. (2018). Project Information Document (PID). Network Reinforcement and Access Project (P166170), The World Bank.

Karhammar R., Sanghvi A., Fernstrom E., Aissa M., Arthur J., Tulloch J., Davies I., Bergman S. and Mathur S. (2006). Sub-Saharan Africa: Introducing Lowcost Methods in Electricity Distribution Networks. ESMAP Technical Paper 104/06.

Karki N.R. (2004). Reducing the Cost of Rural Electrification: A Key to Improve the Quality of Life in Rural Areas in Developing Countries. 2004 International Conference on Power
System Technology-POWERCON, 447-452.

Kashem M.A. and Ledwich G. (2004). Distributed Generation as Voltage Support for Single Wire Earth Return Systems. IEEE Transactions on Power Delivery, 19(3): 1002-1011. DOI: 10.1109/TPWRD.2003.822977.

Kashem M.A. and Ledwich G. (2002). Impact of Distributed Generation on Protection of Single Wire Earth Return Lines. Electric Power Systems Research, 62(1): 67-80. https://doi.org/10.1016/S03787796(02)00031-7

Kavi M., Mishra Y. and Vilathgamuwa D.M. (2016). Detection and Identification of High Impedance Faults in Single Wire Earth Return Distribution Networks. IEEE Australasian Universities Power Engineering Conference-AUPEC2016, $1-6$. DOI: 10.1109/AUPEC.2016.7749341.

Kersting W.H. (2005). The Modeling and Analysis of Parallel Distribution Lines. IEEE 2005 Rural Electric Power Conference, 1-7. DOI: 10.1109/REPCON.2005.1436300.

Kersting W.H. and Green R.K. (2011). The Application of Carson's Equation to the Steady-State Analysis of Distribution Feeders. 2011 IEEE/PES Power Systems Conference and Exposition, 1-6. DOI: 10.1109/PSCE.2011.5772579.

Kessides I.N., Bogetic Z. and Maurer L. (2007). Current and Forthcoming Issues in the South African Electricity Sector. World Bank Policy Research Working Paper 4197.

Khator S.K. and Leung L.C. (1997). Power Distribution Planning: A Review of Models and Issues. IEEE Transactions on Power Systems, 12(3): 1151-1159. DOI:10.1109/59.630455.

Kimambo C.Z. and Nielsen T.K. (2012). Potential of Small-Scale Hydropower for Electricity Generation in Sub- 
Saharan Africa. ISRN Renewable Energy, 2-3.

Louie H., O'Grady E., Van Acker V., Szablya S., Kumar N.P. and Podmore R. (2015). Rural Off-grid Electricity Service in Sub-Saharan Africa. IEEE Electrification Magazine, 7-15. DOI: 10.1109/MELE.2014.2380111.

Lowry S.N., Oo A.M.T. and Robinson G. (2012). Deployment of Low Voltage Switched Capacitors on Single Wire Earth Return Networks. 22nd Australasian Universities Power Engineering Conference (AUPEC), 15.

Luciano B.A., Inacio R.C. and Silva P.P. (2012). Performance of Single Wire Earth Return Transformers with Amorphous Alloy Core in a Rural Electric Energy Distribution System. Materials Research, 15(5): 801-804. DOI: $10.1590 / \mathrm{S} 1516-$ 14392012005000045.

Mahanthege S.D. (2015). Technological and Cost-Effective Selection Procedure for Rural Electrification Systems. M.Sc. Dissertation. University of Moratuwa, Sri Lanka.

Mandeno L. (1947). Rural Power Supply Especially in Back Country Areas. New Zealand Institution of Engineers, 33(1947). New Zealand Institute of Engineers, Wellington, New Zealand.

Maunsell Limited (2006). Review of Solomon Islands Electricity Act and Rural Electrification Framework - Final Report. Prepared for Pacific Islands Energy Policy and Strategic Action Planning (PIEPSAP) and Solomon Islands Department of Energy.

Mayer J., Hosseinzadeh N. and Wolfs P. (2006). Reactor Solutions for Voltage Control of SWER Systems. in Kalam, A. (ed), Australasian Universities Power Engineering Conference AUPEC 2006. Victoria University, Melbourne, Australia.

Meijer A.C. (1995). Suitability of Single Wire Earth Return (SWER) Systems for Rural Electrification in Tanzania.
Master Thesis, Eindhoven University of Technology (TUE), The Netherlands.

Mirazimiabarghouei S.J. (2017). Distributed Static Compensator (DSTATCOM) for Voltage Support in Single Wire Earth Return (SWER) Networks. Doctoral Thesis, University of Southern Queensland, Australia.

Mirazimiabarghouei S.J., Ahfock A. and Helwig A. (2016). Single Wire Earth Return (SWER) System Voltage Support Using Four Quadrant DSTATCOM. 2016 IEEE International Conference on Power and Energy (PECon), 228-233. DOI: 10.1109/PECON.2016.7951564.

Momoh I.O., Jibril Y., Jimoh B., Abubakar A.S., Ajavi O., Abubakar A., Sulaiman S.H. and Yusuf S.S. (2019). Effect of an Optimal Conductor Size Selection Scheme for Single Earth Wire Return Power Distribution Networks for Rural Electrification. J. Science Technology and Education, 7(3): 286-295. ISSN: 2277-0011. www.atbuftejoste.com. Accessed on 17th July 2020.

Monteagudo R.M. (2014). Circuitos de Distribución Monofásicos con Retorno por Tierra. Diploma Work, Departamento de Electroenergética, Facultad de Ingeniería Eléctrica. Santa Clara: Universidad Central Marta Abreu de Las Villas.

National Electricity Regulator (NER) (2001). Electricity Supply Statistics for South Africa. National Electricity Regulator of South Africa, Pretoria, South Africa.

Nebi E., Yuksel H., Sagir D., Yilmaz I., Koc M., Cebeci M.E., Tor O.B. and Guven A.N. (2017). Feasibility of Distributing Electric Power through Single-Phase Transformers at Rural Regions of Turkey based on Rural Characteristic Indices. IEEE Power and Energy Conference at Illinois (PECI), 1-6. DOI:10.1109/PECI.2017.7935728.

Neste C.W., Hull R., Hawk J.E., Phani A., Unsworth J. and Thundat T. (2016). Electrical Excitaion of the Local Earth 
for Resonant, Wireless Energy Transfer. Wireless Power Transfer, 3(2): 117125. doi:10.1017/wpt.2016.8.

Ngowi J.M., Bangens L. and Ahlgren E.O. (2019). Benefits and Challenges to Productive Use of Off-Grid Rural Electrification: The Case of MiniHydropower in Bulongwa-Tanzania. Energy for Sustainable Development, 53:

97-103.

https://doi.org/10.1016/j.esd.2019.10.00 1 .

Nkom B. (2017). Modelling of Transformer and Medium Voltage Powerline Channels for Data Communication on Single Wire Earth Return Distribution Grids. Doctoral Thesis, School of Engineering of the Auckland University of Technology, Australia.

Nkom B., Taylor A.P.R. and Baguley C. (2018). Narrowband Modeling of Single-WireEarth Return Distribution Lines. IEEE Transactions on Power Delivery, 33(4): 1565-1575. DOI: 10.1109/TPWRD.2017.2775189.

Nobbs R.K. (2012). Development of Advanced SWER Models for the Ergon Energy Network. Bachelor Dissertation, University of Southern Queensland, Australia.

Parmar V. (2016). Benefit Cost Analysis of Solar Power Over On-Grid Electricity for Residential Systems: Is Photovoltaic Technology Really Effective? Master Thesis, Texas A\&M University, Australia.

Rudnick H., Mutale J., Chattopadhyay D. and Saint R. (2014). Studies in Empowerment: Approaches to Rural Electrification Worldwide. IEEE Power and Energy Magazine, 35-41. DOI: 10.1109/MPE.2014.2317960.

SADC (2010). SADC Regional Energy Access Strategy and Action Plan. SADC Energy Programme, with Support of European Union Energy Initiative (EUEI).

SADC Statistical Yearbook (2015). Southern African Development
Community: Towards a Common Future. Gaborone: SADC Statistical Yearbook.

Samra B.S. (1972). An Analysis of Single Wire Earth Return (SWER) System for Rural Electrification. Masters Thesis 506, Department of Electrical and Computer Engineering, University of Missouri--Rolla, USA. https://scholarsmine.mst.edu/masters th eses/5062

Shammah A.A.E., Azmy A.M., Simonds P. and El-Ela A.A. (2013). Optimal Sitting and Sizing of Capacitor Banks in Distribution Networks using Heuristic Algorithms. Journal of Electrical Systems, 9(1): 1-12.

Sidhu A.S., Pollit M.G. and Anaya K.L. (2018). A Social Cost Benefit Analysis of Grid-Scale Electrical Energy Storage Projects: A Case Study. Applied Energy, 212: 881-894. https://doi.org/10.1016/j.apenergy.2017. 12.085

Solange N.M. (2017). Design of a Single Wire Earth Return (SWER) Power Distribution System and Improvement of its Voltage Profile Using Capacitors. M.Sc. Dissertation. Pan African University, Nairobi, Kenya.

Song R., Lu S., Sirojan T., Phung B.T. and Ambikairajah E. (2017). Power Quality Monitoring of Single-Wire-EarthReturn Distribution Feeders. 2017 International Conference on High Voltage Engineering and Power Systems (ICHVEPS), 404-409. DOI: 10.1109/ICHVEPS.2017.8225879.

Sri Lanka Energy Managers Association (SLEMA). (2020). Study Report on Estimation of External Cost of Thermal Power Generation. Public Utilities Commission of Sri Lanka, Final Draft Report.

Sumaya R.J., Nkom B. and Nair N.-K.C. (2019). Island Power Operation with Single-Wire Earth Return (SWER), Solar PV and Diesel GenerationMarinduque, Philippines Case Study. 2019 29th Australasian Universities 
Power Engineering Conference (AUPEC), 1-7. DOI: 10.1109/AUPEC48547.2019.214527.

The Africa Electrification Initiative (AEI) (2012). Institutional Approaches to Electrification: The Experience of Rural Energy Agencies/Rural Energy Funds in Sub-Saharan Africa. Dakar, Senegal.

The World Bank (2014). Improving the Quality of Engineering Education and Training in Africa. The World Bank Report No. 86062.

The World Bank. (2006). Sub-Saharan Africa: Introducing Low-Cost Methods in Electricity Distribution Networks. Washington D.C.: World Bank.

United Nations Educational, Scientific and Cultural Organization (UNESCO) (2010). Engineering: Issues Challenges and Opportunities for Development. UNESCO Report, Paris: UNESCO.

Vo T.H., Ravishankar J. and Fletcher J.E. (2013). Assessment of Distributed Generation on the Efficiency of Single Wire Earth Return Systems. Advanced Materials Research. 622-623: 1887$1891 . \quad$ doi: 10.4028/www.scientific.net/AMR.622623.1887 .
Wolfs P. (2013). A Scott Transformer based Single to Three Phase Power Converter for SWER Applications. 2013 Australasian Universities Power Engineering Conference (AUPEC), 16. DOI: 10.1109/AUPEC.2013.6725381.

Wolfs P.J. (2005). Capacity Improvements for Rural Single Wire Earth Return Systems. 2005 International Power Engineering Conference, 1-8. DOI: 10.1109/IPEC.2005.206925.

Wolfs P.J., Hosseinzadeh N. and Senini S.T. (2007). Capacity Enhancement for Aging Distribution Systems Using Single Wire Earth Return. 2007 IEEE Power Engineering Society General Meeting, $\quad 1-8$. DOI: 10.1109/PES.2007.385451.

Yuan G. (2015). Rural Electrification Goes Local-Recent Innovations in Renewable Generation, Energy Efficiency, and Grid Modernization. IEEE Electrification Magazine, 16-24. DOI: 10.1109/MELE.2014.2380193.

Zoomers A. (2014). Context, Challenges, and Obstacles in Rural Electrification. IEEE Power and Energy Magazine, 2634. DOI: 10.1109/MPE.2014.2315916. 